\title{
Applications of Critical Shear Crack Theory to Punching of Reinforced Concrete Slabs with Transverse Reinforcement
}

\author{
by Miguel Fernández Ruiz and Aurelio Muttoni
}

The traditional approach of codes of practice for estimating the punching strength of shear-reinforced flat slabs is based on the assumption that concrete carries a fraction of the applied load at ultimate while the rest of the load is carried by the shear reinforcement. Concrete contribution is usually estimated as a fraction of the punching strength of members without shear reinforcement. The ratio between the concrete contribution for members with and without shear reinforcement is usually assumed constant, independent of the amount of shear reinforcement, flexural reinforcement ratio, and bond conditions of the shear reinforcement. The limitations of such an approach are discussed in this paper and a new theoretical model, based on the critical shear crack theory, is presented to investigate the strength and ductility of shear-reinforced slabs. The proposed approach is based on a physical model and overcomes most limitations of current codes of practice. Its application to various punching shear reinforcement systems is also detailed in the paper and its results are compared to available test data.

Keywords: critical shear crack theory; flat slabs; punching shear; shear reinforcement; two-way shear.

\section{INTRODUCTION}

Punching shear reinforcement is used to improve both the punching shear strength and the ductility of flat slabs. Many punching shear reinforcement systems are currently available. Such systems can be distributed in the slab near the columns (for example, studs, stirrups), placed on top of the columns (that is, steel shearheads or mushrooms), or be a combination of the previous systems. In this paper, the behavior and strength of slabs with distributed shear reinforcement under monotonic and axis-symmetric loading will be investigated.

Considering distributed shear reinforcement, a reinforced concrete flat slab may develop three different punching failure modes (Fig. 1): crushing of the concrete struts near the column, punching within the shear-reinforced zone, and punching outside the shear-reinforced zone. The governing failure mode can thus be estimated as the one leading to the minimum strength of the slab

$$
V_{R}=\min \left(V_{R, \text { crush }} ; V_{R, \text { in }} ; V_{R, \text { out }}\right)
$$

In most approaches and codes of practice, checking the crushing strength $V_{R, c r u s h}$ is usually performed by limiting the maximum punching shear strength with respect to the punching strength of slabs without shear reinforcement (ACI $318-05^{1}$ ) or by considering a reduced compressive strength of concrete struts near the column $\left(\mathrm{EC}^{2}\right)$.

Checking the punching strength outside the shear-reinforced zone $\left(V_{R, \text { out }}\right)$ allows determination of the zone that has to be shear-reinforced. A similar formulation to that of punching shear in slabs without transverse reinforcement is typically used, but the control perimeter ${ }^{2}$ and/or the shear strength ${ }^{1}$ is modified to suitable values. (a)

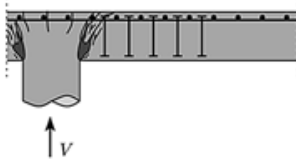

(c)

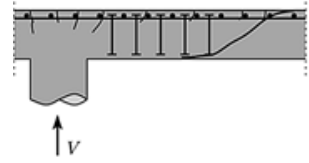

(b)
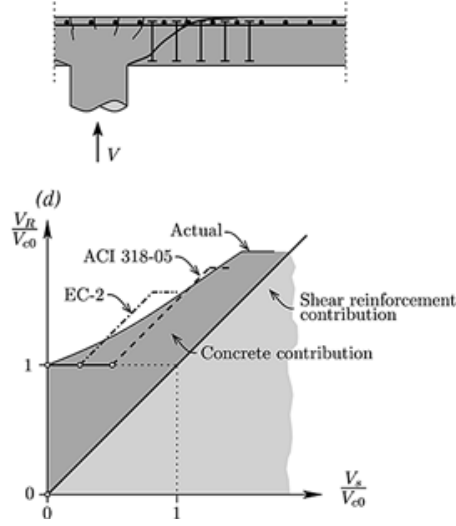

Fig. 1-Possible failure modes in flat slab with punching shear reinforcement: (a) crushing of compression strut; (b) yielding of shear reinforcement with crack localization within shear-reinforced zone; (c) punching shear outside shear-reinforced zone; and (d) comparison of current design approaches (ACI 318-05 and EC2 ${ }^{2}$ ) and actual behavior.

Dimensioning punching shear reinforcement is usually performed by checking the punching strength within the shear-reinforced zone $\left(V_{R, i n}\right)$. Most codes of practice estimate such strength according to the following format

$$
V_{R, i n}=\eta_{c} \cdot V_{c 0}+\eta_{s} \cdot V_{s 0}
$$

where $V_{c 0}$ is the punching shear strength of the slab without shear reinforcement and $V_{s 0}$ is the force that can be carried by the shear reinforcement within the punching cone at yielding. Thus, the contribution of concrete results in $\eta_{c} \cdot V_{c 0}$, whereas the contribution of the shear reinforcement is $\eta_{s}$. $V_{s 0}$, where $\eta_{c}$ and $\eta_{s}$ are factors whose respective values are lower than or equal to 1.0 .

The contribution of concrete $\left(\eta_{c} \cdot V_{c 0}\right)$ is reduced with respect to the punching shear strength without shear reinforcement $\left(V_{c 0}\right)$. This fact is justified because wider shear cracks develop in shear-reinforced slabs, thus reducing the ability of concrete to transfer shear. ${ }^{3}$ The coefficient $\eta_{c}$ is usually considered constant. For instance, ACI 318-05 proposes $\eta_{c}=0.50$ and $\mathrm{EC} 2^{2}$ proposes $\eta_{c}=0.75$. It should be noted that most codes of practice give empirical formulations for the contribution of concrete $\left(V_{c 0}\right)$. Thus, all problems

ACI Structural Journal, V. 106, No. 4, July-August 2009

MS No. S-2007-405.R1 received July 7, 2008, and reviewed under Institute publication policies. Copyright (C) 2009, American Concrete Institute. All rights reserved, including the making of copies unless permission is obtained from the copyright proprietors. Pertinent discussion including author's closure, if any, will be published in the May-June $2010 \mathrm{ACI}$ Structural Journal if the discussion is received by January 1, 2010. 
Miguel Fernández Ruiz is a Lecturer and Research Scientist at the Ecole Polytechnique Fédérale de Lausanne (EPFL), Lausanne, Switzerland. He received his diploma in civil engineering and his PhD from the Polytechnical University of Madrid, Madrid, Spain in 2001 and 2004, respectively. His research interests include the serviceability behavior of structures, bond, shear and punching shear, and the modeling of structural concrete using stress fields.

ACI member Aurelio Muttoni is Professor and Head of the Structural Concrete Laboratory at the EPFL. He received his diploma and PhD in civil engineering from the Swiss Federal Institute of Technology, Zurich, Switzerland, in 1982 and 1989, respectively. His research interests include the theoretical basis of the design of reinforced concrete structures, shear and punching shear, fiber-reinforced high-strength concrete, soil-structure interaction, and the conceptual design of bridges.

related to such empirical formulations ${ }^{4}$ are also inherited by members with shear reinforcement.

With respect to the shear-reinforcement contribution $\left(\eta_{s} \cdot V_{s 0}\right)$, some codes limit the stress in the shear reinforcement at failure ${ }^{2}\left(\eta_{s}<1.0\right)$. Limiting the allowable stress (and thus the allowable strain) in the shear reinforcement is logical because concrete can only carry shear forces if crack widths remain controlled. For instance, in EC2, ${ }^{2}$ the design (factored) value of the yield strength in the shear reinforcement is limited to $f_{y w d}=(250+0.25 d[\mathrm{~mm}]) \mathrm{MPa}(36.2+0.92 d$ [in.]) ksi. In ACI 318-05, ${ }^{1}$ the maximum yield strength in the shear reinforcement is $414 \mathrm{MPa}(60 \mathrm{ksi})$. The angle of the punching shear cone (where the shear reinforcement is considered active) also varies for different codes (for example, 45 degrees for ACI $318-05^{1}$ and 34 degrees for EC2 ${ }^{2}$ ).

Figure 1(d) compares ACI $318-05^{1}$ and EC2 ${ }^{2}$ approaches, where it has been assumed that $\eta_{s}=1.0$. Also, a theoretical curve describing the actual contributions of a shear-reinforced concrete slab is drawn. Contrary to the approaches followed by codes of practice, the value of $\eta_{c}$ varies with the amount of shear reinforcement, bond conditions of the shear reinforcement, and longitudinal reinforcement ratio. It can be noted that codes of practice provide rather conservative estimates for low shear reinforcement ratios. These differences are reduced as the amount of shear reinforcement increases and the concrete contribution may even be overestimated (refer to Fig. 1(d)).

In this paper, a different approach for estimating the punching strength of shear-reinforced slabs is introduced. The approach is based on a physical model derived from the critical shear crack theory (CSCT). ${ }^{3-6}$ This theory has thus far been applied to members without transverse reinforcement by adopting the hypothesis that a single shear crack localizes the strains in the critical shear region.

As previously shown, ${ }^{3,4,6}$ the width of the critical shear crack can be correlated to a physical parameter (a reference strain for beams in shear and the rotation of a slab for punching shear in flat slabs), which allows determination of the deformation capacity of a member at ultimate. Taking advantage of the compatibility conditions introduced by CSCT (in this case, the rotation of the slab), the contributions of concrete and the shear reinforcement are estimated depending on the various geometrical and mechanical parameters of the specimen (and not by adopting a constant contribution). Also, because the theory relies on a mechanical model, bond conditions can be introduced for the shear reinforcement, allowing one to describe the mechanical behavior of various shear reinforcement systems.

\section{RESEARCH SIGNIFICANCE}

Current methods for the design of punching shear reinforcement rely on empirical formulations to estimate the contributions of concrete and shear reinforcement at failure. This approach, (a)

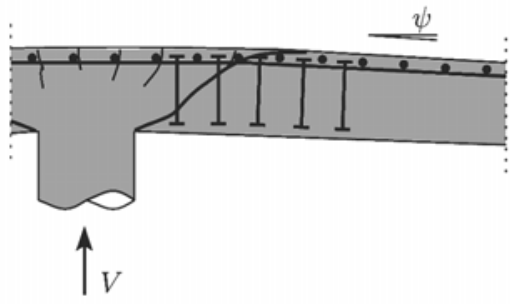

(b)

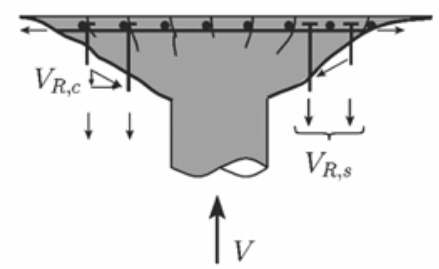

(c)

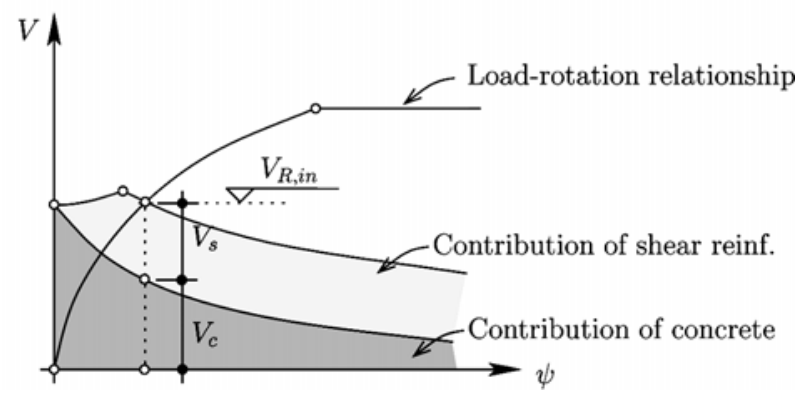

Fig. 2-Punching within shear-reinforced zone: (a) localization of strains within shear-reinforced zone; (b) contribution of concrete and of shear reinforcement; and (c) punching

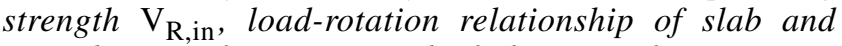
contribution of concrete and of shear reinforcement as function of rotation in slab.

in some cases, leads to very conservative estimates of punching shear strength of flat slabs, but may also overestimate the contribution of concrete or the shear reinforcement. This paper introduces a physical model based on CSCT that allows one to estimate, on a rational basis, the contributions of concrete and of shear reinforcement to the punching shear strength. Because the proposed approach is based on a physical model, it allows to account for the layout of shear reinforcement as well as the diameter, bond conditions, reinforcement ratio, and other mechanical and geometrical parameters. Thus, it is applicable to a wide number of shear reinforcement systems.

\section{FAILURE CRITERION BASED ON CRITICAL SHEAR CRACK THEORY}

Within the shear-reinforced zone, failure develops when a critical shear crack opens, localizing the strains as shown in Fig. 2(a). In this case, a fraction of the applied shear can still be carried by concrete (this contribution is limited by the opening of the critical shear crack and by its roughness), while the remaining part of the shear force is carried by the shear reinforcement. The punching strength can thus be written as (refer to Fig. 2(b) and (c))

$$
V_{R, i n}=V_{c}+V_{s}
$$

The concrete contribution $V_{c}$ can be estimated according to CSCT assuming that a single crack develops in the failure zone. ${ }^{5}$ Based on this theory, Muttoni ${ }^{4}$ proposed the 
(a)

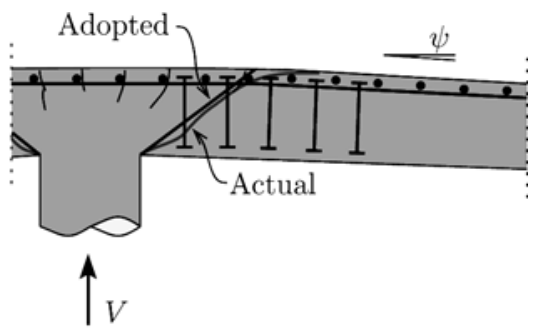

(b)

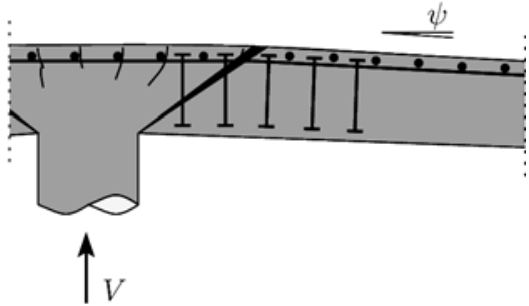

(c)

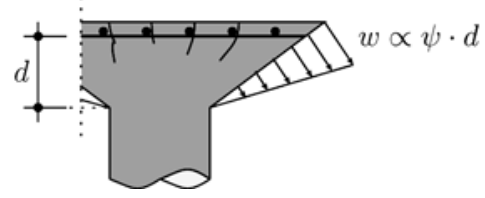

Fig. 3-Punching shear strength in shear-reinforced slabs based on critical shear crack theory: (a) actual and adopted geometry for critical shear crack localizing strains; (b) assumed slab kinematics with opening of critical shear crack; and (c) corresponding crack widths for assumed geometry and kinematics.

following failure criterion, correlating well with results of 99 punching shear tests without transverse reinforcement

$$
\begin{gathered}
V_{c}=\frac{3}{4} \cdot \frac{b_{0, i n t} \cdot d \sqrt{f_{c}^{\prime}}}{1+15 \cdot \frac{\psi \cdot d}{d_{g 0}+d_{g}}} \text { SI units }(\mathrm{N}, \mathrm{mm}) \\
V_{c}=9 \cdot \frac{b_{0, \text { int }} \cdot d \sqrt{f_{c}^{\prime}}}{1+15 \cdot \frac{\psi \cdot d}{d_{g 0}+d_{g}}} \text { U.S. customary units (psi, in.) }
\end{gathered}
$$

where $\psi$ is the maximal rotation of the slab; $b_{0, \text { int }}$ is the control perimeter (defined at $d / 2$ beyond the tip of the crack, typically at the face of the column [refer to Fig. 2(a)], but other possible failure locations can be investigated); $d$ is the average effective depth of the member; $f_{c}$ is the compressive strength of concrete; $d_{g}$ is the maximum aggregate size; and $d_{g 0}$ is a reference aggregate size set to $16 \mathrm{~mm}$ (0.63 in.).

The contribution of the shear reinforcement can be estimated according to CSCT using its main hypothesis, ${ }^{4,5}$ which establishes that the opening of the shear critical crack is proportional to the product of the rotation of the slab times the effective depth of the member (refer to Fig. 3)

$$
w \propto \psi \cdot d
$$

Equation (5) can thus be rewritten as (a)

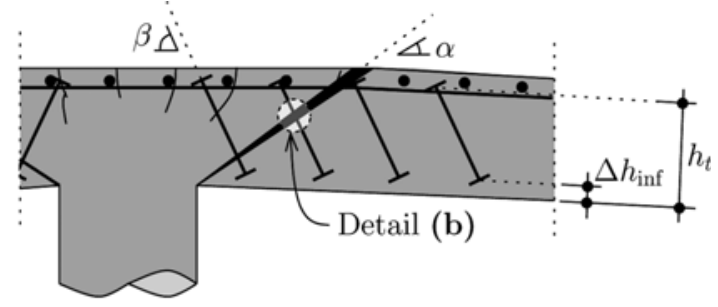

(b)
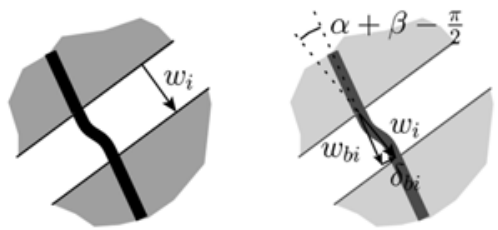

(c)

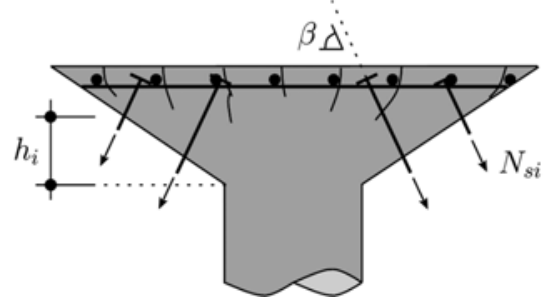

Fig. 4-Contribution of the shear reinforcement: (a) geometrical parameters of shear reinforcement and of critical shear crack; (b) opening of critical shear crack and longitudinal and transverse relative slips at shear reinforcement; and (c) contribution of shear reinforcement within the punching cone.

$$
w=\kappa \cdot \psi \cdot d
$$

where $\kappa$ is a constant whose value is proposed in this paper as $\kappa=0.50$. Assuming that the critical shear crack is straight (and thus the failure surface is a cone) and that the center of rotation of the crack is located at its tip, the following expressions are obtained for the relative displacements of the crack lips parallel $\left(w_{b i}\right)$ and perpendicular $\left(\delta_{b i}\right)$ to the shear reinforcement (Fig. 4)

$$
\begin{aligned}
& w_{b i}=\kappa \cdot \psi \cdot h_{i} \cdot \cos \left(\alpha+\beta_{i}-\frac{\pi}{2}\right) \\
& \delta_{b i}=\kappa \cdot \psi \cdot h_{i} \cdot \sin \left(\alpha+\beta_{i}-\frac{\pi}{2}\right)
\end{aligned}
$$

where $h_{i}$ is the vertical distance between the tip of the crack and the point where the shear reinforcement crosses the critical shear crack, $\alpha$ is the angle of the critical shear crack (proposed to be equal to $\pi / 4$ ), and $\beta_{i}$ is the angle between the shear reinforcing bar and the slab plane (Fig. 4). Thus, the stress in the shear reinforcement $\left(\sigma_{s i}\right)$ can be evaluated from $w_{b i}$ (which is in turn a function of the rotation of the slab, $\psi$ ), depending on the bond properties of the shear reinforcement. If the dowel action of the shear reinforcement is neglected, the contribution of the shear reinforcement becomes

$$
V_{s}=\sum_{i=1}^{n} \sigma_{s i}(\psi) \cdot A_{s i} \cdot \sin \left(\beta_{i}\right)
$$




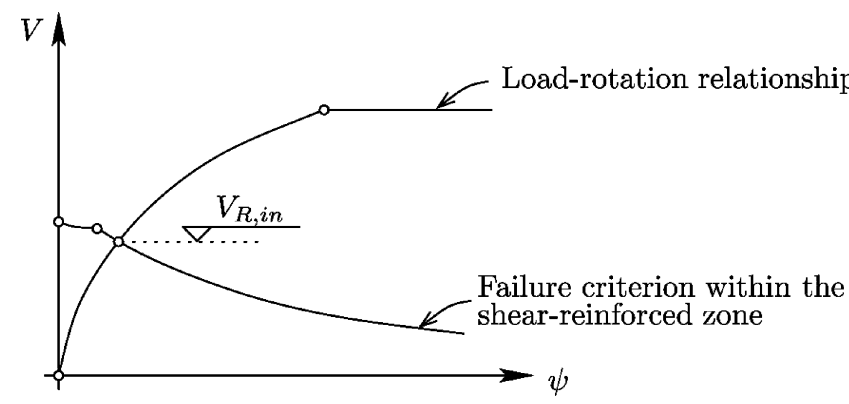

Fig. 5-Failure within shear-reinforced zone $\mathrm{V}_{\mathrm{R}, \text { in }}$ : failure criterion and load-rotation relationship.

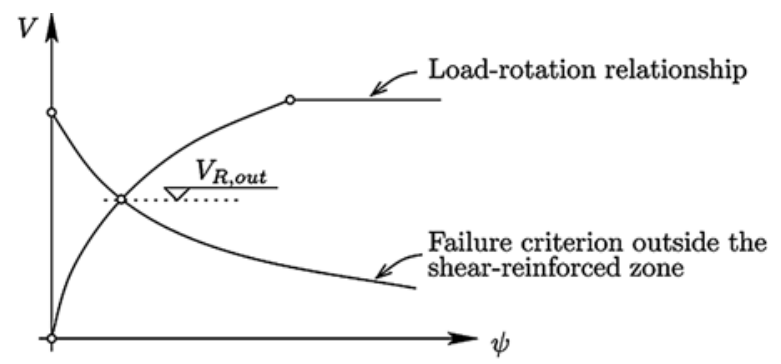

(a)

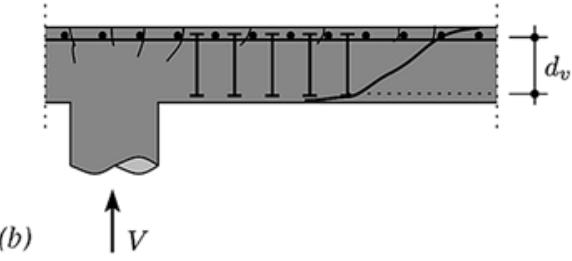

Fig. 6-Failure outside shear-reinforced zone $\mathrm{V}_{\mathrm{R} \text { out: (a) failure }}$ criterion and load-rotation relationship; and $(b)$ reduced effective depth $\mathrm{d}_{\mathrm{v}}$.

where $A_{s i}$ is the cross-sectional area of the shear reinforcement. Appendix $1^{*}$ details the analytical expressions for $\sigma_{s i}(\psi)$ for a number of shear reinforcement systems with various bond conditions. Expressions for other systems can be derived by analogy.

Finally, once the concrete and the shear reinforcement contributions are known, the punching shear strength of the member can be obtained by intersecting the failure criterion $\left(V_{c}+V_{s}\right)$ with the load-rotation relationship describing the behavior of the slab, as shown in Fig. 2(c) and (5). A simplified expression describing the rotation of the slab $(\psi)$ as a function of the applied load is given by the following formula (introduced in Reference 4 from a number of simplifications of a more general, analytically-derived expression)

$$
\psi=1.5 \cdot \frac{r_{s}}{d} \cdot \frac{f_{y}}{E_{s}} \cdot\left(\frac{V}{V_{\text {flex }}}\right)^{\frac{3}{2}}
$$

where $r_{s}$ is the distance from the edge of the column to the line of contraflexure of bending moments (that for regular flat slabs

\footnotetext{
*The Appendix is available at www.concrete.org in PDF format as an addendum to the published paper. It is also available in hard copy from ACI headquarters for a fee equal to the cost of reproduction plus handling at the time of the request.
}

can be taken equal to $0.22 \ell$, where $\ell$ is the span length of the flat slab), $f_{y}$ is the yield strength of the flexural reinforcing steel, $E_{s}$ is the modulus of elasticity of the flexural reinforcing steel, and $V_{\text {flex }}$ is the load necessary to develop the plastic mechanism of the slab (a detailed solution can be found in References 4 and 7).

It should be noted that cases may exist where the shear reinforcement is not fully yielded when the load-rotation relationship intersects the failure criterion. In this case, if the possible increase in the force carried by the shear reinforcement is larger than the decrease in the force carried by the concrete, the strength of the slab may be larger than assumed in Fig. 5. This potential increase, however, is neglected in the present study.

\section{CHECK OF OTHER FAILURE MODES Punching outside the shear-reinforced zone}

Punching outside the shear-reinforced zone develops by localization of the strains in a critical shear crack (Fig. 1(a)). According to CSCT, the punching shear strength outside the shear-reinforced zone $\left(V_{R, \text { out }}\right)$ can be estimated as the point where the load-rotation relationship of the slab (Eq. (9)) intersects the failure criterion outside the shear-reinforced zone (Fig. 6(a))

$$
\begin{gathered}
V_{R, \text { out }}=\frac{3}{4} \cdot \frac{b_{0, \text { out }} \cdot d_{v} \sqrt{f_{c}^{\prime}}}{1+15 \cdot \frac{\psi \cdot d}{d_{g 0}+d_{g}}} \text { SI units }(\mathrm{N}, \mathrm{mm}) \\
V_{R, \text { out }}=9 \cdot \frac{b_{0, \text { out }} \cdot d_{v} \sqrt{f_{c}^{\prime}}}{1+15 \cdot \frac{\psi \cdot d}{d_{g 0}+d_{g}}} \text { U.S. customary units (psi, in.) }
\end{gathered}
$$

where $d_{v}$ is the reduced effective depth shown in Fig. 6(b) (to account for pullout of shear reinforcement as will be explained later) and $b_{0, \text { out }}$ is the control perimeter (defined at $d / 2$ beyond the outer layer of shear reinforcement and considering $4 d$ as the maximum effective distance between two concentric rows of shear reinforcement). This approach provides good fitting to test data and is slightly conservative because the rotation of the slab is assumed to be concentrated in the shear-critical crack, although a fraction of the total rotation develops within the shear-reinforced zone.

\section{Crushing of concrete struts near support region}

Crushing of the concrete struts near the column has also been reported as a governing failure mode in some cases. ${ }^{8}$ The compressive strength of the compression struts is strongly influenced by their state of transverse strains, which in turn are functions of the rotation of the slab (because wider cracks develop for larger rotations). On that basis, the crushing strength of a reinforced concrete slab is estimated as

$$
\begin{aligned}
& V_{R, \text { crush }}=\lambda \cdot \frac{3}{4} \cdot \frac{b_{0, \text { col }} \cdot d \sqrt{f_{c}^{\prime}}}{1+15 \cdot \frac{\psi \cdot d}{d_{g 0}+d_{g}}} \text { SI units }(\mathrm{N}, \mathrm{mm}) \\
& V_{R, \text { crush }}=\lambda \cdot 9 \cdot \frac{b_{0, \text { col }} \cdot d \sqrt{f_{c}^{\prime}}}{1+15 \cdot \frac{\psi \cdot d}{d_{g 0}+d_{g}}} \text { U.S. cust. units (psi, in.) }
\end{aligned}
$$


where $b_{0, \text { col }}$ is the control perimeter (defined at $d / 2$ of the edge of the column or support region). The parameter $\lambda$ is set equal to 3.0 for well-anchored shear reinforcement (that is, headed studs). Otherwise, this value is limited to 2.0. The crushing strength of the slab is obtained again at the point where the failure criterion (Eq. (11)) intersects the load-rotation relationship of the slab (Eq. (9)), as shown in Fig. 7.

\section{Pullout of anchorages}

As shown by other authors, 9,10 an anchorage can be pulled out from a concrete block if insufficient embedment length is available (refer to Fig. 8(a)). Applications of this failure mode to punching in flat slabs has recently been investigated. 8,11

It should be noted that a direct application of the results of pullout tests 9,10 to shear reinforcement is not straightforward because the conditions in which the pullout tests are performed are generally different from the actual conditions of a stud inside a shear-reinforced flat slab. At the tension face, the pullout strength of the shear reinforcement is increased by the dowel action of the flexural reinforcement (if the shear reinforcement is enclosing the flexural reinforcement).

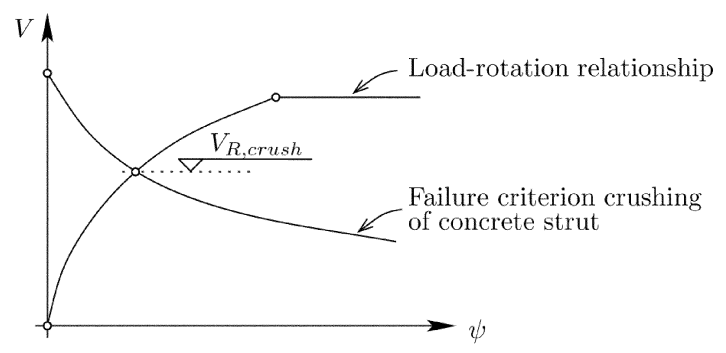

Fig. 7-Failure by crushing of the concrete strut $\mathrm{V}_{\mathrm{R}, \mathrm{crush}}$ : failure criterion and load-rotation relationship.
Also, at the compression face, the pullout strength of the stud is increased by the favorable state of stresses (with compressive stresses in two directions) and by the dowel action of the compression reinforcement (if the shear reinforcement is enclosing it).

Regarding some constructive rules (stud spacing and diameter, and shear reinforcement enclosing the flexural reinforcement), the risk of pullout of the shear reinforcement within the shear-reinforced zone is limited. This is confirmed by the results of several tests ${ }^{8,11}$ where cracks developing from the anchorages of the shear reinforcement did not develop a pullout failure surface. This fact can, for instance, be appreciated in the saw-cut of Specimen Z3 by Beutel $^{8}$ (Fig. 8(b)) in which the width of the cracks originating at the anchorages of the studs are controlled by the next perimeter of studs and, thus, a pullout surface like that of Fig. 8(a) does not develop.

The width of the cracks developing from the anchorages of the outer layer of shear reinforcement, however, is not controlled by any other ring of shear reinforcement. Thus, the pullout failure surfaces may join, eventually leading to a punching shear failure outside the shear-reinforced zone. Figure 8(c) shows, for instance, the saw-cut of Specimen P1I by Beutel, ${ }^{8}$ where the development of a punching cone from the pullout cracks of the outer layer of shear reinforcement is clearly visible. This fact, as previously stated, is considered in the theoretical model by introducing a reduced effective depth $d_{v}$ in Eq. (10) (refer to Fig. 8(c)), when performing the check of the strength outside the shear-reinforced zone.

Another failure mode has been reported ${ }^{12}$ as the development of horizontal cracks along the upper and lower surface of anchorages leading to delamination of the member (Fig. 8(d)). This failure mode may become governing when the shear reinforcement is not enclosing the longitudinal reinforcement.

(a)
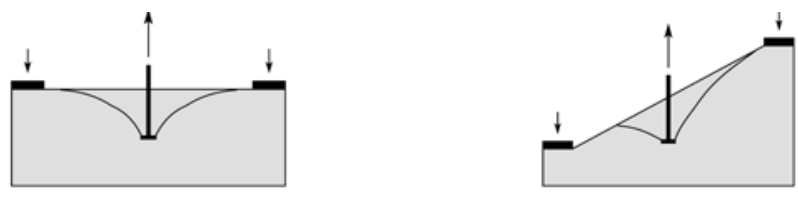

(b)

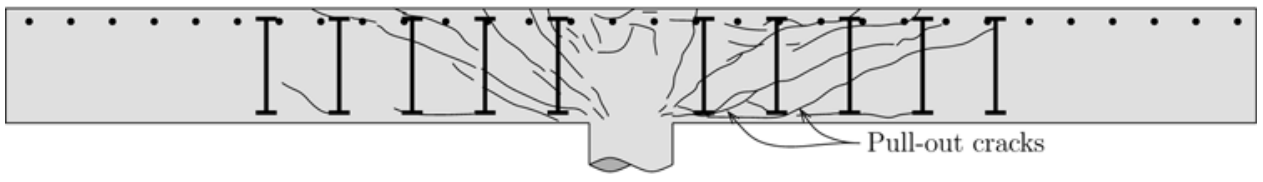

(c)

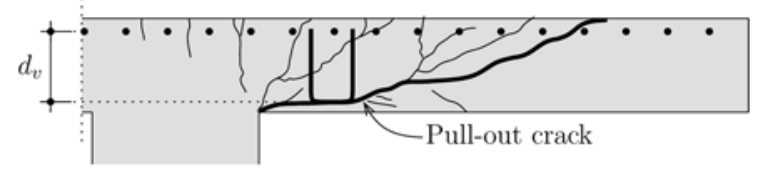

(d)

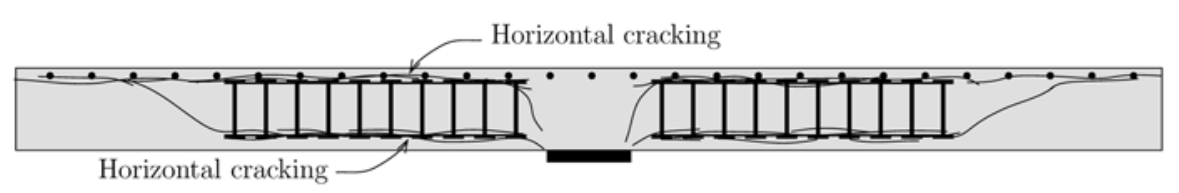

Fig. 8-Development of pullout cracks: (a) typical test setup for pullout specimens ${ }^{10}$; (b) development of pullout cracks without development of pullout cones (Specimen Z3 by Beutel $^{8}$ ); (c) punching outside shear-reinforced zone by development of pullout cracks (Specimen PII by Beutel ${ }^{8}$ ); and (d) failure mode by delamination according to Regan and Samadian. ${ }^{12}$ 


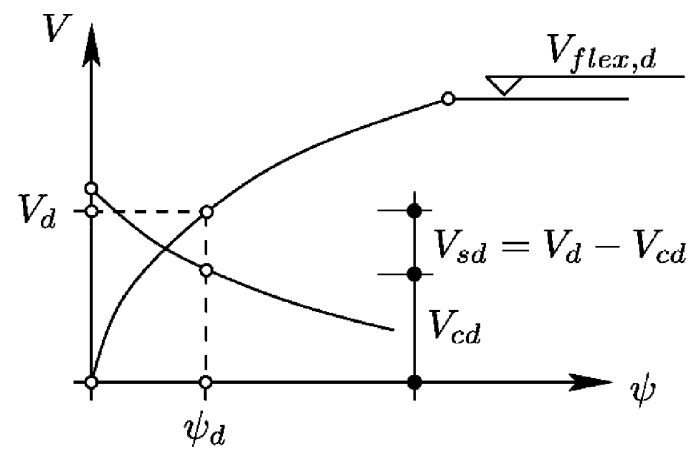

Fig. 9-Application of code-like formulation to design of shear reinforcement.

\section{CODE-LIKE FORMULATION}

Based on the previous approach, a simplified code-like formulation can also be proposed for design purposes. To that aim, the same three failure modes (failure within and outside the shear-reinforced zone, together with crushing of the compression struts), have to be checked.

The punching shear strength within the shear-reinforced zone can be calculated on the basis of Eq. (3) as

$$
V_{R d}=V_{c d}+V_{s d}
$$

With respect to the shear force carried by concrete $\left(V_{c d}\right)$, a characteristic formulation of the failure criterion of the $\mathrm{CSCT}^{4}$ (reaching a target $5 \%$ fractile) has to be adopted

$$
\begin{gathered}
V_{c d}=\frac{1}{\gamma_{c}} \cdot \frac{2}{3} \cdot \frac{b_{0, i n t} \cdot d \sqrt{f_{c k}}}{1+20 \cdot \frac{\psi \cdot d}{d_{g 0}+d_{g}}} \text { SI units }(\mathrm{N}, \mathrm{mm}) \\
V_{c d}=\phi \cdot 8 \cdot \frac{b_{0, i n t} \cdot d \sqrt{f_{c}^{\prime}}}{1+20 \cdot \frac{\psi \cdot d}{d_{g 0}+d_{g}}} \text { U.S. customary units (psi, in.) }
\end{gathered}
$$

where $f_{c k}$ and $f_{c}^{\prime}$ are the characteristic and specified compressive strengths of concrete, respectively (according to the European and North American practices, a relationship between both strengths is discussed in Reference 13); and where $\gamma_{c}$ is the partial safety factor of concrete (1.5 according to European practice); and $\phi$ is the strength reduction factor for punching ( 0.75 according to North American practice).

For slabs with smooth shear reinforcement, and based on the expressions provided in Appendix 1 of this paper, the term $V_{s d}$ can be easily estimated assuming for all shear reinforcements a mean stress equal to that of a shear reinforcement placed at $0.5 d$ from the border of the support region

$$
V_{s d}=\frac{E_{s} \cdot \psi}{6} \cdot A_{s w} \leq f_{y w d} \cdot A_{s w}
$$

where $A_{s w}$ is the amount of shear reinforcement within a perimeter at $d$ from the edge of the support region, and $f_{y w d}$ is the design yield strength of the shear reinforcement.

For slabs with deformed shear reinforcement, it can be assumed an increase on the shear reinforcement stress due to bond as (refer to Regime 3 in Appendix 1)
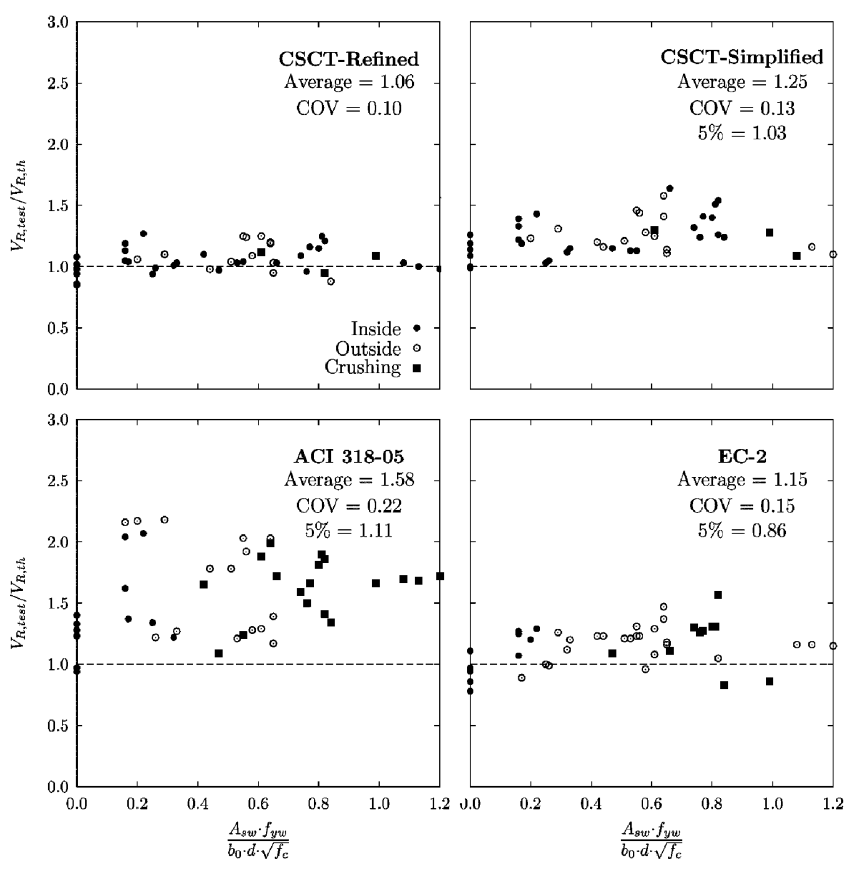

Fig. 10-Comparison between measured and estimated punching shear strengths (see details in Table 1): proposed model using critical shear crack theory (CSCT) with its refined and design (simplified) formulation; ACI 318-05 ${ }^{1}$ and EC2. ${ }^{2}$

$$
V_{s d}=\left(\frac{E_{s} \cdot \psi}{6}+\tau_{b} \frac{d}{d_{b}}\right) \cdot A_{s w} \leq f_{y w d} \cdot A_{s w}
$$

where $\tau_{b}$ is the average bond stress, whose value can be adopted as $5 \mathrm{MPa}$ (725 psi) for ordinary cases.

The use of Eq. (12) for design purposes is rather simple. As shown in Fig. 9, the rotation at failure $\left(\psi_{d}\right)$ can be calculated for a given value of the shear force $\left(V_{d}\right)$ using the loadrotation relationship defined in Eq. (9). This rotation is then used to calculate the contribution of concrete $\left(V_{c d}\right)$ using Eq. (13). The remaining part $\left(V_{d}-V_{c d}=V_{s d}\right)$ has to be carried by the shear reinforcement, where the necessary amount can thus be determined directly on the basis of Eq. (14) or (15).

Checking the punching strength outside the shearreinforced area can be performed on the basis of Eq. (13) by introducing the suitable control perimeter $b_{0 \text {,out }}$ and the reduced effective depth $d_{v}$ as defined previously in Eq. (10). The crushing strength can also be calculated on the basis of Eq. (13) by multiplying this strength by factor $\lambda$ as explained in Eq. (11).

\section{COMPARISON OF TEST RESULTS TO CODES OF PRACTICE}

Figure 10 compares the punching shear strength of the tests detailed in Table 1 (with the shear reinforcement systems shown in Fig. 11) to the results of the proposed model and those of some codes of practice. ${ }^{1,2}$ The tests are sorted along the ordinate using the following ratio (correlated to $V_{s 0} / V_{c 0}$ )

$$
\frac{A_{s w} \cdot f_{y w}}{b_{0} \cdot d \cdot \sqrt{f_{c}^{\prime}}}
$$


where $A_{s w}$ is the amount of shear reinforcement within a perimeter at $d$ from the edge of the support region, $f_{y w}$ is the yield strength of the shear reinforcement, and $b_{0}$ is a control perimeter at $d / 2$ from the edge of the column.
For the proposed model, a good agreement is found (refer to Fig. 10) between the measured punching shear strength in the tests and the calculated punching shear strength, with an average ratio of 1.06 (values over 1.0 mean conservative

Table 1-Comparison of proposed model (refined and design [simplified] formulations), ACI $318-05,{ }^{1}$ and $\mathrm{EC2}^{2}$ with available test data (refer to Fig. 11 for shear reinforcement types) ${ }^{*}$

\begin{tabular}{|c|c|c|c|c|c|c|c|c|}
\hline & \multirow[b]{2}{*}{ Specimen } & \multirow{2}{*}{$\begin{array}{c}\text { Shear reinforcement } \\
\text { types }\end{array}$} & \multirow[b]{2}{*}{$d, \mathrm{~mm}$} & \multirow[b]{2}{*}{$d$, in. } & \multicolumn{4}{|c|}{$V_{\text {test }} / V_{t h}$} \\
\hline & & & & & CSCT average & CSCT simplified & ACI 318-05 & $\mathrm{EC} 2$ \\
\hline \multirow{12}{*}{ Birkle $^{11}$} & S1 & - & 124 & 4.88 & 1.08 & 1.26 & 1.40 & 1.11 \\
\hline & S2 & (b) & 124 & 4.88 & 1.03 & 1.15 & 1.27 & 1.20 \\
\hline & S3 & (b) & 124 & 4.88 & 1.01 & 1.12 & 1.22 & 1.12 \\
\hline & S4 & (b) & 124 & 4.88 & 1.04 & 1.21 & 1.78 & 1.21 \\
\hline & S5 & (b) & 124 & 4.88 & 1.03 & 1.13 & 1.21 & 1.21 \\
\hline & S6 & (b) & 124 & 4.88 & 1.04 & 1.13 & 1.24 & 1.23 \\
\hline & S7 & - & 190 & 7.48 & 1.02 & 1.19 & 1.23 & 0.96 \\
\hline & S8 & (b) & 190 & 7.48 & 0.94 & 1.03 & 1.34 & 1.00 \\
\hline & S9 & (b) & 190 & 7.48 & 1.13 & 1.33 & 1.62 & 1.07 \\
\hline & S10 & - & 260 & 10.2 & 0.86 & 1.00 & 0.97 & 0.78 \\
\hline & S11 & (b) & 260 & 10.2 & 0.99 & 1.05 & 1.22 & 0.99 \\
\hline & S12 & (b) & 260 & 10.2 & 1.04 & 1.19 & 1.37 & 0.89 \\
\hline \multirow{12}{*}{ Gomes and Regan ${ }^{14}$} & S1 & - & 159 & 6.26 & 0.94 & 1.09 & 1.28 & 0.94 \\
\hline & S1A & - & 159 & 6.26 & 0.98 & 1.14 & 1.33 & 0.97 \\
\hline & S2 & (c) & 153 & 6.02 & 1.05 & 1.22 & 2.16 & 1.25 \\
\hline & S3 & (c) & 158 & 6.22 & 1.06 & 1.23 & 2.17 & 1.20 \\
\hline & S4 & (c) & 159 & 6.26 & 1.10 & 1.31 & 2.18 & 1.26 \\
\hline & S5 & (c) & 159 & 6.26 & 0.98 & 1.16 & 1.78 & 1.23 \\
\hline & S6 & (c) & 159 & 6.26 & 1.10 & 1.20 & 1.65 & 1.23 \\
\hline & S7 & (c) & 159 & 6.26 & 1.20 & 1.58 & 2.03 & 1.37 \\
\hline & S8 & (c) & 159 & 6.26 & 1.19 & 1.41 & 1.99 & 1.47 \\
\hline & S9 & (c) & 159 & 6.26 & 1.12 & 1.30 & 1.88 & 1.08 \\
\hline & S10 & (c) & 154 & 6.06 & 1.19 & 1.39 & 2.04 & 1.27 \\
\hline & S11 & (c) & 154 & 6.06 & 1.27 & 1.43 & 2.07 & 1.29 \\
\hline \multirow{11}{*}{ Beutel $^{8}$} & $\mathrm{Z1}$ & (a) & 250 & 9.84 & 0.96 & 1.24 & 1.50 & 1.26 \\
\hline & $\mathrm{Z} 2$ & (a) & 250 & 9.84 & 1.09 & 1.32 & 1.59 & 1.30 \\
\hline & $\mathrm{Z} 3$ & (a) & 250 & 9.84 & 1.21 & 1.54 & 1.86 & 1.57 \\
\hline & $\mathrm{Z} 4$ & (a) & 250 & 9.84 & 1.16 & 1.41 & 1.66 & 1.27 \\
\hline & $\mathrm{Z} 5$ & (a) & 250 & 9.84 & 1.25 & 1.51 & 1.90 & 1.31 \\
\hline & Z6 & (a) & 250 & 9.84 & 1.15 & 1.40 & 1.81 & 1.31 \\
\hline & V4 & (a) & 350 & 13.7 & 0.97 & 1.15 & 1.09 & 1.09 \\
\hline & $\mathrm{P} 1$ & - & 191 & 7.52 & 0.85 & 0.99 & 0.94 & 0.86 \\
\hline & P1-I & (e) & 191 & 7.52 & 1.25 & 1.46 & 2.03 & 1.31 \\
\hline & P1-II & (e) & 191 & 7.52 & 1.24 & 1.44 & 1.92 & 1.23 \\
\hline & P2-I & (e) & 191 & 7.52 & 1.09 & 1.28 & 1.28 & 0.96 \\
\hline Müller et al. ${ }^{15}$ & $\mathrm{P} 22$ & (d) & 153 & 6.04 & 1.09 & 1.28 & 1.66 & 0.86 \\
\hline \multirow{3}{*}{ Stein et al. ${ }^{16}$} & V1 & (b) & 118 & 4.65 & 1.25 & 1.25 & 1.29 & 1.29 \\
\hline & V2 & (b) & 118 & 4.65 & 0.95 & 1.11 & 1.39 & 1.18 \\
\hline & V3 & (b) & 118 & 4.65 & 1.03 & 1.14 & 1.17 & 1.16 \\
\hline \multirow{6}{*}{ Rojek and Keller ${ }^{17,18}$} & 20-I & (f) & 155 & 6.10 & 1.03 & 1.09 & 1.70 & 1.16 \\
\hline & 20-II & (f) & 152 & 5.98 & 0.98 & 1.10 & 1.72 & 1.15 \\
\hline & 20-III & (f) & 150 & 5.90 & 1.00 & 1.16 & 1.68 & 1.16 \\
\hline & $30-\mathrm{I}$ & (f) & 252 & 9.92 & 0.95 & 1.26 & 1.41 & 1.05 \\
\hline & 30-II & (f) & 260 & 10.2 & 0.88 & 1.24 & 1.34 & 0.83 \\
\hline & 30-III & (f) & 254 & 10.0 & 1.03 & 1.64 & 1.72 & 1.11 \\
\hline & & & & Average & 1.06 & 1.25 & 1.58 & 1.15 \\
\hline & & & & $\mathrm{COV}$ & 0.10 & 0.13 & 0.22 & 0.15 \\
\hline
\end{tabular}

*Maximum aggregate size of tests by Stein et al. ${ }^{16}$ equal to $14 \mathrm{~mm}(0.55 \mathrm{in}$.$) , value given by Dilger in private communication; maximum aggregate size of tests by Rojek and$ Keller $^{17,18}$ equal to $16 \mathrm{~mm}$ ( $0.63 \mathrm{in}$.), yield strength of flexural steel = $506 \mathrm{MPa}(73.3 \mathrm{ksi})$, values given by Rojek in private communication. 


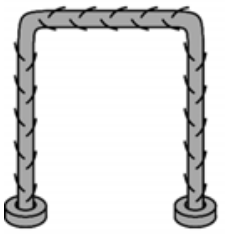

(e)

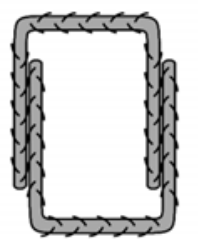

(f)

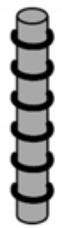

Fig. 11-Shear reinforcement types: (a) deformed stud; (b) smooth stud; (c) steel offcut; (d) headed stirrup; (e) stirrup; and $(f)$ enhanced-bond shear reinforcement.

(a)

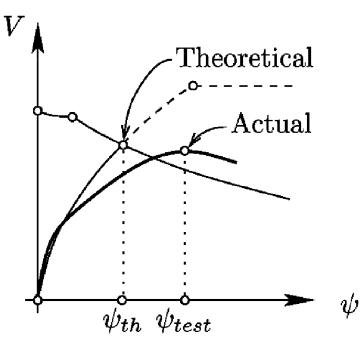

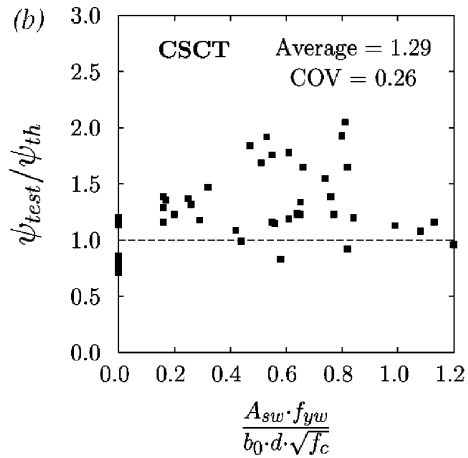

Fig. 12-Comparison between measured and estimated rotations at failure.

estimates) and with a small value of the coefficient of variation $(\mathrm{COV}=10 \%)$. A comparison of the proposed theory using the simplified design formulation (setting material safety factors to 1.0) is also shown in Fig. 10. The average value of the measured-to-estimated punching shear strength increases to 1.25 , with a value of the COV of 0.13 . The ratio for the $5 \%$ fractile is 1.03 , thus leading to a satisfactory safety level (larger than 1.0).

$\mathrm{EC} 2^{2}$ shows a good agreement with respect to the average value of the previous ratio (1.15). Accounting for the COV, however, unsafe results may be obtained in actual designs (5\% fractile below 1.0). ACI $318-05^{1}$ leads to larger scatters than $\mathrm{EC} 2 ;^{2}$ however, the rather conservative estimates of the measured-to-estimated punching shear strength leads to a satisfactory $5 \%$ fractile (above 1.0).

It is interesting to note that with the proposed approach, not only the punching shear strength but also the rotation of the slab can be estimated at failure (refer to Fig. 12). A satisfactory agreement is also found for this parameter with the proposed model with conservative estimates of the rotation at failure in general.

\section{CONTRIBUTIONS OF CONCRETE AND OF SHEAR REINFORCEMENT ACCORDING TO CSCT}

Figure 13(a) shows a circular reinforced concrete slab where the diameter of the shear reinforcing bars $d_{b}$ (deformed studs in this case) is varied together with the flexural

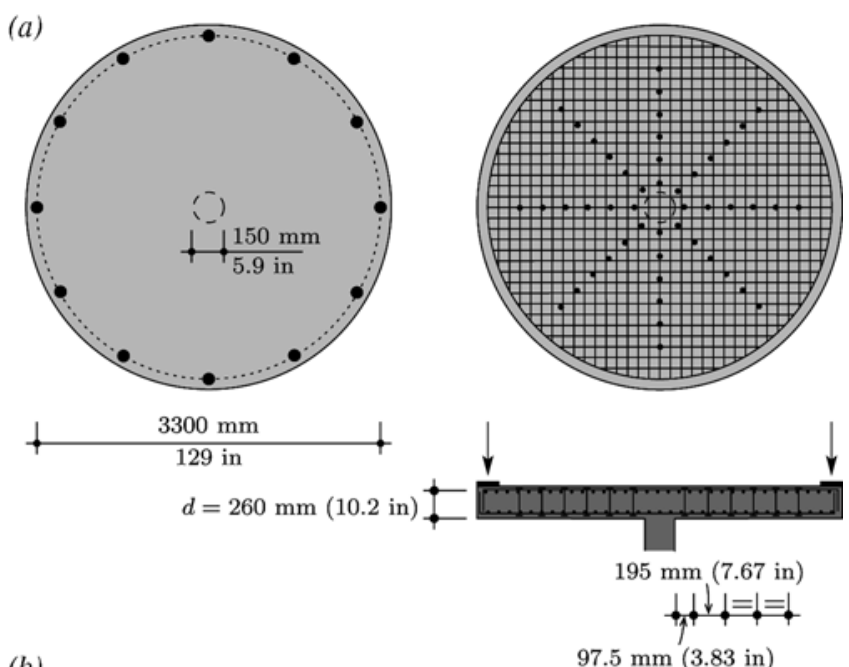

(b)
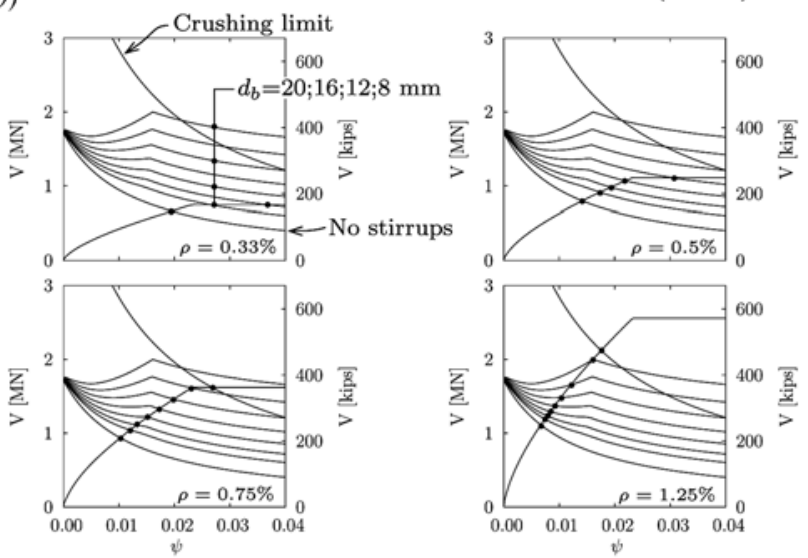

(c)

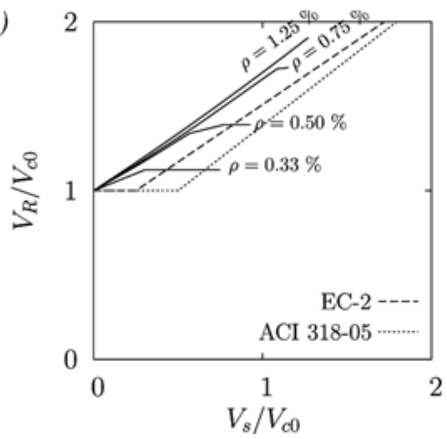

Fig. 13-Influence of flexural reinforcement ratio and amount of shear reinforcement on contributions of steel and concrete: (a) investigated specimen $(\mathrm{d}=260 \mathrm{~mm}$ [10.2 in.]; $\mathrm{f}_{\mathrm{c}}=25 \mathrm{MPa}\left[3600\right.$ psi]; $\mathrm{d}_{\mathrm{g}}=32 \mathrm{~mm}$ [1.25 in.]; $\mathrm{f}_{\mathrm{y}}=\mathrm{f}_{\mathrm{yw}}=$ $500 \mathrm{MPa}[72 \mathrm{ksi}]$ ); (b) failure criteria and estimated failure loads; and (c) influence of flexural reinforcement ratio on concrete contribution.

reinforcement ratio $\rho$. The results, in terms of load-rotation diagrams, are presented in Fig. 13(b) for various cases. For the lowest flexural reinforcement ratio $(\rho=0.33 \%)$, the bending strength of the slab is reached even for very small amounts of shear reinforcement. As the flexural reinforcement ratio increases, the role of the amount of shear reinforcement in the strength of the member becomes more evident. It can be noted that, for the case where $\rho=1.25 \%$, the bending strength of the slab cannot be reached independently of the amount of shear reinforcement because crushing of the struts becomes governing. Based on the previous results, the 
(a)

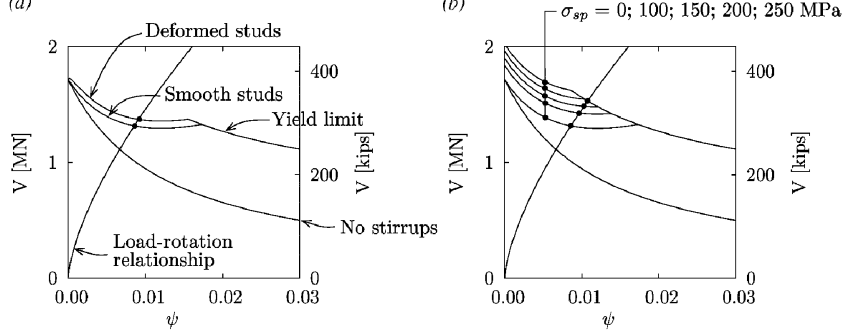

Fig. 14-Influence of bond conditions on punching shear strength (same specimen as in Fig. 13(a)): (a) punching shear strength with smooth and with deformed studs; and (b) punching shear strength for prestressed smooth studs (refer to Fig. 15(b) in Appendix 1).

contributions of the shear reinforcement and of concrete at failure can be estimated and plotted in a format similar to that of codes of practice (refer to Eq. (2) and Fig. 1). The results (Fig. 13(c)) show that codes of practice underestimate the contribution of concrete for small amounts of shear reinforcement (small values of the ratio $V_{s} / V_{c 0}$ ), but may overestimate it for large amounts of shear reinforcement.

The contributions of concrete and shear reinforcement also vary depending on the bond conditions of the member. Figure 14(a) shows the results obtained for the previous slab (Fig. $13(\mathrm{a})$ ) with $\rho=1.25 \%$ and $d_{b}=14 \mathrm{~mm}(0.55$ in.) when deformed and smooth studs are used. According to the theoretical model, the punching strength with deformed studs increases because the strains in the shear reinforcement for the same rotation are larger. A similar effect is also shown in Fig. 14(b), where the smooth studs are prestressed at various levels. When prestressing is increased, the punching strength of the member also increases according to the theoretical model because the stress in the studs is larger for the same rotation of the slab. Both effects are not included in current design methods.

\section{SUMMARY AND CONCLUSIONS}

This paper investigates the punching shear strength of reinforced concrete flat slabs with shear reinforcement. Its main conclusions are:

1. The contribution of concrete to the punching shear strength of flat slabs is not constant, contrary to what is assumed in most codes of practice. Codes of practice usually underestimate this contribution for low amounts of shear reinforcement and may overestimate it for large amounts of shear reinforcement;

2. A physical model based on the critical shear crack theory can be used to investigate the punching shear strength in members with transverse reinforcement leading to simple analytical expressions;

3. Based on the critical shear crack theory, it is demonstrated that the contribution of concrete to the punching shear strength is reduced for large rotations of the slab. This reduction depends on some parameters such as, for instance, the flexural reinforcement ratio or the amount of shear reinforcement;

4. The proposed model can be applied to a number of shear reinforcing systems and to investigate the role of the various geometrical and mechanical parameters;

5. The model accounts for the position, concrete cover, and other geometrical parameters of the shear reinforcement. Bond conditions and prestressing of the shear reinforcement can be easily introduced with the proposed physical model. Such conditions show a non-negligible influence in the punching shear strength, although most codes of practice do not consider them;

6 . Very good agreement is found when comparing the proposed approach to available test data; and

7. A simplified design formulation can be derived on the basis of CSCT leading to a satisfactory safety level when compared to available test results.

\section{NOTATION}

$A_{s w}=$ cross-sectional area of shear reinforcement

$A_{s w 1}=$ sum of cross-sectional areas of shear reinforcements placed at one perimeter (reinforcements at same distance from support region)

$b_{0}=$ perimeter of critical section

$b_{0, c o l}=$ perimeter of critical section at $d / 2$ of face of column

$b_{0, \text { int }}=$ perimeter of critical section (check of punching within shearreinforced zone)

$b_{0, \text { out }}=$ perimeter of critical section (check of punching shear outside shear-reinforced zone)

$d \quad=$ distance from extreme compression fiber to centroid of longitudinal tensile reinforcement

$d_{b} \quad=$ diameter of reinforcing bar

$d_{g} \quad=$ maximum diameter of aggregate

$d_{g 0}=$ reference aggregate size $(16 \mathrm{~mm}[0.63 \mathrm{in.}])$

$d_{v} \quad=$ reduced effective depth

$E_{s} \quad=$ modulus of elasticity of reinforcement

$f_{c} \quad=$ average compressive strength of concrete (cylinder)

$f_{y} \quad=$ yield strength of flexural reinforcement

$f_{y w} \quad=$ yield strength of shear reinforcement

$f_{y w, e f}=$ effective yield strength of shear reinforcement

$f_{y w d}=$ design yield strength of shear reinforcement

$h=$ vertical distance between tip of crack and point where shear reinforcement crosses critical shear crack

$k \quad=\quad$ size effect factor in EC2

$\ell=$ span of slab, length

$\ell_{a i}=$ distance between point where shear reinforcement is crossed by critical shear crack and closest head of shear reinforcement

$\ell_{a s}=$ distance between point where shear reinforcement is crossed by critical shear crack and head of shear reinforcement found farthest from that point

$\ell_{s} \quad=$ stud length

$r_{s}=$ distance between column of slab and line of contraflexure of moments

$s_{r}=$ distance between perimeters of shear reinforcement

$\begin{array}{lll}s_{r} & = & \text { shear force }\end{array}$

$V_{c}=$ concrete contribution to punching shear strength

$V_{c 0}=$ punching shear strength of slab without shear reinforcement

$V_{c d}=$ design concrete contribution to punching shear strength

$V_{d}=\operatorname{design}$ (factored) action

$V_{\text {flex }}=$ shear force associated with flexural capacity of slab

$V_{\text {flex }, d}=$ shear force associated with design flexural capacity of slab

$V_{R}=$ punching shear strength

$V_{R} \quad=$ design punching shear strength

$V_{R, \text { crush }}=$ punching shear strength (governing crushing of concrete struts)

$V_{R, \text { in }}=$ punching shear strength (governing failure within shearreinforced zone)

$V_{R, \text { out }}=$ punching shear strength (governing failure outside shearreinforced zone)

$V_{s}=$ shear reinforcement contribution to punching shear strength

$V_{s 0} \quad=$ force that can be carried by shear reinforcement within punching cone at yielding

$V_{s d}=$ design shear reinforcement contribution to punching shear strength

$V_{\text {test }}=$ experimental punching shear strength

$w=$ critical shear crack width

$w_{b} \quad=$ relative displacement parallel to shear reinforcement

$\alpha=$ angle of critical shear crack with compression face of slab

$\beta=$ angle of shear reinforcement with compression face of slab

$\delta_{b}=$ relative displacement perpendicular to shear reinforcement

$\varepsilon_{s} \quad=$ steel strain

$\phi=$ strength reduction factor

$\gamma_{c} \quad=$ partial safety factor of concrete

$\eta_{c}=$ efficiency factor for contribution of concrete

$\eta_{s}=$ efficiency factor for contribution of shear reinforcement 
$\kappa=$ critical shear crack opening factor

$\lambda=$ crushing strength parameter

$\rho=$ flexural reinforcement ratio

$\sigma_{s} \quad=$ steel stress

$\sigma_{s p} \quad=$ prestress

$\tau_{b} \quad=$ bond strength

$\psi=$ rotation of slab outside column region

$\psi_{d} \quad=$ rotation of slab outside column region (design value)

\section{REFERENCES}

1. ACI Committee 318, "Building Code Requirements for Structural Concrete (ACI 318-05) and Commentary (318R-05)," American Concrete Institute, Farmington Hills, MI, 2005, 430 pp.

2. Eurocode 2, "Design of Concrete Structures-Part 1-1: General Rules and Rules for Buildings," CEN, EN 1992-1-1, Brussels, Belgium, 2004, 225 pp.

3. Muttoni, A., and Fernandez Ruiz, M., "Shear Strength of Members without Transverse Reinforcement as a Function of Critical Shear Crack Width," ACI Structural Journal, V. 105, No. 2, Mar.-Apr. 2008, pp. 163-172.

4. Muttoni, A., "Punching Shear Strength of Reinforced Concrete Slabs without Transverse Reinforcement," ACI Structural Journal, V. 105, No. 4, July-Aug. 2008, pp. 440-450.

5. Muttoni, A., and Schwartz, J., "Behaviour of Beams and Punching in Slabs without Shear Reinforcement," IABSE Colloquium, V. 62, Zurich, Switzerland, 1991, pp. 703-708.

6. Muttoni, A., "Shear and Punching Strength of Slabs without Shear Reinforcement," Beton- und Stahlbetonbau, V. 98, No. 2, 2003, pp. 74-84. (in German)

7. Nielsen, M. P., Limit Analysis and Concrete Plasticity, second edition, CRC Press, Boca Raton, FL, 1999, 908 pp.

8. Beutel, R., "Punching of Flat Slabs with Shear Reinforcement at Inner Columns," Rheinisch-Westfälischen Technischen Hochschule Aachen, Aachen, Germany, 2002, 267 pp. (in German)
9. Fuchs, W.; Eligehausen, R.; and Breen, J. E., "Concrete Capacity Design (CCD) Approach for Fastening to Concrete," ACI Structural Journal, V. 92, No. 1, Jan.-Feb. 1995, pp. 73-94.

10. Regan, P. E., "Shear Reinforcement of Flat Slabs," Proceedings of the International Workshop on Punching Shear Capacity of RC Slabs, TRITA-BKN, Bulletin 57, 2000, pp. 99-107.

11. Birkle, G., "Punching of Flat Slabs: The Influence of Slab Thickness and Stud Layout," Department of Civil Engineering, University of Calgary, Calgary, AB, Canada, 2004, 152 pp.

12. Regan, P. E., and Samadian, F., "Shear Reinforcement against Punching in Reinforced Concrete Flat Slabs," The Structural Engineer, V. 79, No. 10, 2001, pp. 24-31.

13. Reineck, K.-H.; Kuchman, D. A.; Kim, K. S.; and Marx, S., "Shear Database for Reinforced Concrete Members without Shear Reinforcement," ACI Structural Journal, V. 100, No. 2, Mar.-Apr. 2003, pp. 240-249.

14. Gomes, R., and Regan, P. E., "Punching Strength of Slabs Reinforced for Shear with Offcuts of Rolled Steel I-Section Beams," Magazine of Concrete Research, V. 51, No. 2, 1999, pp. 121-129.

15. Müller, F.-X.; Muttoni, A.; and Thurlimann, B., "Punching Tests on Flat Slabs with Recesses," Institut für Baustatik und Konstruktion, ETH Zürich, Report Nr. 7305-5, Birkhäuser Verlag Basel-Boston-Stuttgart, 1984, 118 pp. (in German)

16. Stein, T.; Ghali, A.; and Dilger, W., "Distinction between Punching and Flexural Failure Modes of Flat Plates," ACI Structural Journal, V. 104, No. 3, May-June 2007, pp. 357-365.

17. Rojek, R., and Keller, T., "Punching Tests using Reinforcement with Enhanced Bond, Structural Analysis and Design Approaches," Beton-und Stahlbetonbau, V. 102, No. 8, 2007, pp. 584-556. (in German)

18. Rojek, R., and Keller, T., "Punching Tests with HFV-Studs," Fachhochschule Augsburg, Kompetenzzentrum Konstruktiver Ingenieurbau, 2006, 270 pp. (in German) 